\title{
THE INFLUENCE OF LOADING ECCENTRICITY ON BUCKLING OF AXIALLY COMPRESSED IMPERFECT COMPOSITE CYLINDERS
}

\author{
E. Eglitis ${ }^{1}$, K. Kalnins ${ }^{1}$ and O. Ozolinsh ${ }^{1}$ \\ ${ }^{1}$ Institute of Materials and Structures, Riga Technical University, LV-1658, Riga, Latvia
}

Composite shells are very efficient structural elements that an engineer can use to design structures with the highest strength-to-weight and stiffness-to-weight ratios. However, reliable design of composite shells is a very sophisticated task partly because of the imperfection sensitivity of compressed shells [1-2]. Buckling of axially compressed composite cylinders has been studied extensively over the years, yet little information can be found in the literature on buckling behavior of these shells under eccentric loading. Buckling of composite cylinders under concentric compression and with introduced eccentricity is investigated experimentally and numerically in this paper. Particular attention has been given to imperfection sensitivity of the shells. Series of glass fiber reinforced plastic cylinders have been tested under different load eccentricities (see Fig. 1 a) to validate the corresponding nonlinear numerical analyses performed in this study. Good agreement between experimental and numerical results has been achieved through use of ABAQUS/Explicit finite element code and introduction of initial imperfections. Both the experimental and the numerical results show that the knock-down factor raises with the increase of the loading eccentricity (see Fig. $1 \mathrm{~b})$.

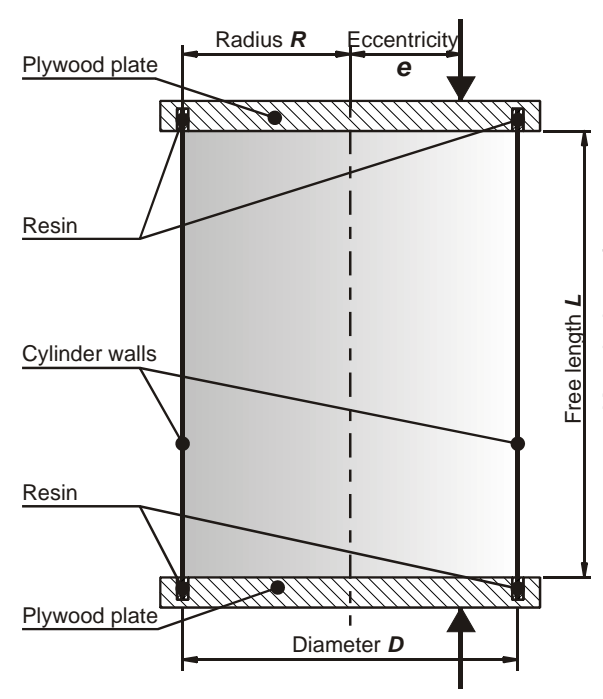

$a$

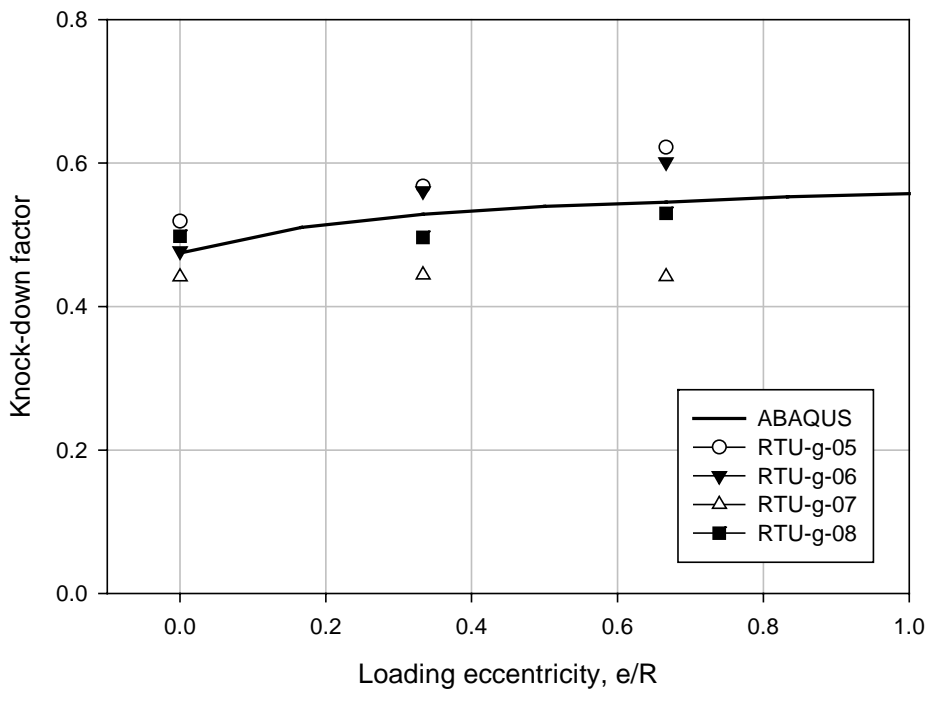

$b$

Fig. 1. $a$-specimen configuration; $b$-comparison of numerically obtained knock-down factors with results of validation experiments

\section{REFERENCES}

1. J. Singer, J. Arbocz, T. Weller, "Buckling Experiments: Experimental Methods in Buckling of Thin-Walled Structures," John Wiley and Sons, New York (2004).

2. E. Eglītis, K. Kalniņš, O. Ozoliņš, G. Teters, "An experimental and numerical study on the dynamic buckling of cylindrical composite shells," Abstracts of XV International Conference Mechanics of Composite Materials, Riga, Latvia, p. 76 (2008). 